\title{
BMJ Prevalence of, and risk factors for, HIV, OPen hepatitis $B$ and $C$ infections among men who inject image and performance enhancing drugs: a cross-sectional study
}

\author{
Vivian D Hope, ${ }^{1,2}$ Jim McVeigh, ${ }^{3}$ Andrea Marongiu, ${ }^{1}$ Michael Evans-Brown, ${ }^{4}$ \\ Josie Smith, ${ }^{5}$ Andreas Kimergård, ${ }^{6}$ Sara Croxford, ${ }^{1}$ Caryl M Beynon, ${ }^{3}$ \\ John V Parry, ${ }^{1,2}$ Mark A Bellis, ${ }^{3}$ Fortune Ncube $^{1}$
}

To cite: Hope VD, McVeigh J, Marongiu A, et al. Prevalence of, and risk factors for, HIV, hepatitis $B$ and $C$ infections among men who inject image and performance enhancing drugs: a cross-sectional study. BMJ Open 2013;3: e003207. doi:10.1136/ bmjopen-2013-003207

- Prepublication history for this paper is available online. To view these files please visit the journal online (http://dx.doi.org/10.1136/ bmjopen-2013-003207).

Received 13 May 2013 Revised 25 June 2013 Accepted 22 July 2013

For numbered affiliations see end of article.

Correspondence to Dr Vivian Hope; vivian.hope@phe.gov.uk

\section{ABSTRACT}

Objective: To describe drug use, sexual risks and the prevalence of blood-borne viral infections among men who inject image and performance enhancing drugs (IPEDs).

Design: A voluntary unlinked-anonymous crosssectional biobehavioural survey.

Setting: 19 needle and syringe programmes across England and Wales.

Participants: 395 men who had injected IPEDs.

Results: Of the participants (median age 28 years), $36 \%$ had used IPEDs for $<5$ years. Anabolic steroids $(86 \%)$, growth hormone (32\%) and human chorionic gonadotropin (16\%) were most frequently injected, with $88 \%$ injecting intramuscularly and $39 \%$ subcutaneously. Two-thirds also used IPEDs orally. Recent psychoactive drug use was common (46\% cocaine, $12 \%$ amphetamine), $5 \%$ had ever injected a psychoactive drug and $9 \%$ had shared injecting equipment. 'Viagra/Cialis' was used by $7 \%$, with $89 \%$ reporting anal/vaginal sex in the preceding year (20\% had $5+$ female-partners, 3\% male-partners) and $13 \%$ always using condoms. Overall, $1.5 \%$ had HIV, $9 \%$ had antibodies to the hepatitis B core antigen (anti-HBc) and 5\% to hepatitis C (anti-HCV). In multivariate analysis, having HIV was associated with: seeking advice from a sexual health clinic; having had an injection site abscess/wound; and having male partners. After excluding those reporting male partners or injecting psychoactive drugs, $0.8 \%$ had HIV, $8 \%$ anti-HBc and 5\% anti-HCV. Only $23 \%$ reported uptake of the hepatitis $B$ vaccine, and diagnostic testing uptake was poor (31\% for HIV, $22 \%$ for hepatitis C).

Conclusions: Previous prevalence studies had not found HIV among IPED injectors. HIV prevalence in this, the largest study of blood-borne viruses among IPED injectors, was similar to that among injectors of psychoactive drugs. Findings indicate a need for targeted interventions.

\section{ARTICLE SUMMARY}

Article focus

- The Vulnerability to infection of people who inject drugs is widely recognised; however, studies have rarely focused on users of image and performance enhancing drugs. These drugs can be used to change one's appearance for aesthetic reasons, as well as to improve performance.

- Over the last decade, the number of men using needle and syringe programmes who report injecting image and performance enhancing drugs has risen in England and Wales; as a result, there has been increased concern about the levels of bloodborne viral infections in this group.

- This study describes the nature of drug use and the risk behaviours in this population, as well as the prevalence of HIV, hepatitis B and C.

Key messages

- The overall prevalence of HIV among men injecting image and performance enhancing drugs was similar to that among those injecting psychoactive drugs in England and Wales. Previous prevalence studies of people who inject image and performance enhancing drugs had not detected HIV.

- When the results of this study are compared with those of a previous study undertaken in England and Wales in the mid-1990s, they suggest that the prevalence of hepatitis B infection among injectors of image and performance enhancing drugs might have increased over time.

- Sexual risk behaviours and psychoactive drug use were common among injectors of image and performance enhancing drugs, and the sharing of injecting equipment was also reported. The uptake of diagnostic testing for blood borne-viral infections and the vaccine against hepatitis B was low. 


\section{ARTICLE SUMMARY}

Strengths and limitations of this study

- This study recruited image and performance enhancing drug users through needle and syringe programmes. Injectors of these drugs who are not in contact with these services may have a different risk profile and levels of infection.

- Oral-fluid testing was used to detect antibodies to HIV, hepatitis B and C; however, tests on these samples for anti-HCV and anti-HBc have reduced sensitivity.

- This is the largest study of blood-borne viruses among men who inject image and performance enhancing drugs; however, the sample size still restricts its power. Consequently, caution is needed when attempting to generalise these findings.

\section{INTRODUCTION}

The vulnerability of people who inject drugs (PWID) to HIV and other infections is widely recognised; however, studies have focused on individuals who inject psychoactive drugs (such as opiates and stimulants) rather than on those who inject drugs to enhance image and performance. $^{1-4}$ The number of injectors of image and performance enhancing drugs (IPEDs) in contact with needle and syringe programmes (NSPs) has grown substantially in the $\mathrm{UK}^{5}$ and there has been increasing concern about the use of IPEDs and the associated harms in the UK and elsewhere. ${ }^{35-11}$

A range of illicit drugs can be injected with the aim of changing image and performance. These drugs range from tanning drugs, such as 'Melanotan-II', ${ }^{12}$ to those used in body-building, such as human growth hormone. $^{3}{ }^{13}$ The most commonly injected and studied IPEDs are anabolic steroids (AS). ${ }^{35}$ IPEDs are taken both orally and by injection, with some being predominantly injected and others being taken only orally. Many users of these substances also take an array of different drugs. ${ }^{3} 514$ The use, and particularly the injection of IPEDs has been associated with a range of harms including infections caused by bacteria $^{15-19}$ and blood-borne viruses (BBVs). ${ }^{60-25}$

In England and Wales (E\&W), surveillance of HIV and viral hepatitis among PWID is undertaken through an annual unlinked-anonymous survey ${ }^{26}{ }^{27}$ targeted at injectors of psychoactive drugs. A very small number of IPED injectors participated in this survey ${ }^{20}$; among the 149 sampled during the $1990 \mathrm{~s}, 2 \%$ had antibodies to the hepatitis B core antigen (anti-HBc, a marker of having ever been infected with hepatitis B virus (HBV))) and none had antibodies to HIV (anti-HIV). ${ }^{20}$ In a surveillance study of NSP clients in Australia, 1.6\% ( $\mathrm{n}=318)$ of those participating over a 10-year period reported steroid injection, with $10 \%$ having antibodies to hepatitis $\mathrm{C}$ virus (anti-HCV) and none having anti-HIV. ${ }^{21}$ Only one other survey of IPED injectors has collected biological samples; this study purposively recruited 63 AS injectors in Victoria, Australia and found that $12 \%$ had anti-HBc, $9.5 \%$ anti-HCV and none anti-HIV. ${ }^{6} \mathrm{~A}$ second
Australian study found that half of the IPED users sampled had ever experienced an injection-related health problem, with $6 \%$ having ever had an abscess. ${ }^{8}$

A number of other UK studies have recruited IPED injectors, principally AS injectors; however, none of these collected biological samples. These studies were mostly small $(\mathrm{N}<100)$, and typically recruited through gyms, ${ }^{28-33}$ with two recruiting gay men. ${ }^{34}{ }^{35}$ The prevalence of ever sharing injecting equipment in these studies ranged from $0.3 \%$ to $6 \%,{ }^{20} 28-3032$ but in one study it was $20 \% .{ }^{33}$ The sharing of drug vials was more common $\left(2.4 \%^{35} ; 9.9 \%^{34}\right.$; $23 \%{ }^{32}$ ). Studies elsewhere have found similar levels of equipment sharing. ${ }^{6}{ }^{8}$ IPED users also report using psychoactive drugs, particularly stimulants, though the reported injection of psychoactive drugs is rare. ${ }^{6} 8283536$ IPED users also tend to have more sexual partners than their comparison groups ${ }^{20} 28$ and report risky sexual behaviours $^{20}{ }^{32}$ and low levels of condom use, ${ }^{28}{ }^{34}$ suggesting an elevated risk for HIV infection through sexual activity.

During 2010 and 2011, in response to the increasing concerns about IPED use, a targeted survey was undertaken as part of the ongoing unlinked-anonymous survey of PWID. The aim of this survey was to describe the: (1) patterns of drug use and injecting risk; (2) sexual behaviours and (3) BBV prevalence among IPED injectors. As far as we are aware, this is the largest study, and the first outside Australia, to purposively recruit IPED injectors to measure the prevalence of anti-HIV, anti-HBc and anti-HCV.

\section{METHODS}

\section{Recruitment}

In E\&W, PWID have been recruited into a voluntary unlinked-anonymous monitoring survey since 1990, and the methodological details of this cross-sectional survey have been published previously. ${ }^{26} 27{ }^{37}$ Briefly, agencies providing services to PWID (eg, NSPs and addiction treatment) at sentinel locations throughout $\mathrm{E} \& \mathrm{~W}$ invite clients who have ever injected to participate. Sentinel sites are selected so as to reflect the geographic distribution and range of services offered to PWID. Those who consent to participate (overall refusal rate during 2010/ 2011, 4.7\%) provide a biological sample and selfcomplete a brief questionnaire focused on psychoactive drug use. ${ }^{26} 27$ The survey has multisite ethics approval. This study purposively recruited IPED injectors through 19 sites that provided NSPs. Participants were recruited either when attending an NSP site or through outreach provision; they provided an oral-fluid sample and selfcompleted a short, specially developed, questionnaire focused on IPED use (types of drug used and routes of administration), related behaviours (injecting practices and sexual behaviours) and health service use.

\section{Laboratory methods}

Oral-fluid specimens were collected using the OraSure device (OraSure Technologies Inc, Pennsylvania, USA). 
These were tested for anti-HIV using an in-house GACELISA with similar performance to GACELISA HIV 1+2 (Abbott Murex Diagnostics Ltd, Dartford, UK). Reactive specimens underwent further testing according to a proven algorithm that included a second ELISA and Western blot (sensitivity and specificity approaches $\left.100 \%^{38}\right)$. Anti-HCV testing employed a previously validated commercial enzyme-immunoassay (Ortho HCV 3.0 SAVe, Ortho Diagnostics) with 92\% sensitivity and $99 \%$ specificity, ${ }^{39}$ and for anti-HBc an in-house IgG classspecific antibody capture EIA procedure was used which had an estimated sensitivity of $75 \%$ and specificity of 99\% (JV Parry and A Judd, personal communication). The oral-fluid sample quality was verified by testing each sample for the presence of a predetermined minimum quantity of total IgG $(1 \mathrm{mg} / \mathrm{L})$ employing an in-house ELISA method.

\section{Analyses}

Descriptive analyses were first undertaken, and then bivariate associations $(\mathrm{p}<0.05)$ between outcome variables (anti-HIV, anti-HBc and anti-HCV positivity, equipment sharing and condom use) and covariates (age, drug use, sexual practice and health services use; table 1) were examined using Fisher's exact (when expected cell frequencies $<5$ ) and Pearson's $\chi^{2}$ tests. Where possible associations were found $(\mathrm{p}<0.10)$, these were further examined through logistic regression models using the forward stepwise procedures to select variables, with selection based on the likelihood ratio test $(p<0.05)$. All analyses were undertaken using SPSS V.19.

\section{RESULTS}

Between May 2010 and May 2011, 400 IPED injectors participated in this study; five $(1.25 \%)$ women were excluded from the analyses (due to the small number). The participants' characteristics and health service usage are summarised in table 1 . Of those reporting their age $(88 \%$, $\mathrm{n}=347)$, a quarter $(27 \%)$ were aged $<25$ years. During the preceding year, $45 \%$ had seen a general practitioner and $28 \%$ had taken the prescribed medication.

\section{Drug use}

Details of the participants' IPED use during the preceding year are given in table 1 . AS were the most commonly injected IPED $(86 \%)$. Over half of the participants reported consuming these orally $(57 \%)$, a third reported injecting growth hormone (32\%) and almost a quarter reported using oral antioestrogens $(23 \%)$. Overall, 65\% ( $n=252)$ had taken an IPED orally during the preceding year, with 58 (23\%) of these having taken two types orally, and 85 (34\%) $\geq 3$ types. Most had injected only one type of IPED during the preceding year; however, $87(22 \%)$ had injected two types and $58(15 \%) \geq 3$ types. Considering injecting and oral use, $71(18 \%)$ had taken two types of IPED and 133 $(34 \%) \geq 3$ during the preceding year.
Those who injected human growth hormone were more likely to be older (aged $>35$ years) than those who had not $(37 \%(47 / 128)$ vs $22 \% \quad(60 / 267), \quad$ p $<0.001)$; there were no other significant differences in the IPEDs used by age. During the preceding year, most of the participants $(74 \%)$ reported that they had usually injected themselves, and the majority $(88 \%)$ had injected intramuscularly (table 1 ).

The participants also reported psychoactive drug use (table 1 ), with $46 \%$ snorting cocaine and $12 \%$ snorting, drinking or swallowing amphetamine during the preceding year. Ever having injected a psychoactive drug (including heroin and cocaine) was reported by $4.8 \%$ (table 1). Those who had injected a psychoactive drug were more likely to report injecting insulin as an IPED than those who had not $(21 \%(4 / 19)$ vs $4.8 \%(18 / 376)$, $\mathrm{p}=0.016)$; there were no other significant differences in the IPEDs used between those who had injected psychoactive drugs and those who had not.

Overall, $8.9 \%$ (95\% CI $6.4 \%$ to $12 \%$ ) reported having ever shared a needle/syringe or drugs vial (table 1); 27 $(6.8 \%)$ had just shared a vial, $6(1.5 \%)$ had just shared a needle/syringe and $2(0.51 \%)$ had shared both. Factors associated with sharing are summarised in table 2. In the multivariable analysis, ever having shared a needle/ syringe or drug vial was associated with having ever injected a psychoactive drug, having sought advice from an sexual health/sexual transmitted infections ( $\mathrm{SH}$ / STI) clinic, subcutaneous injection and having snorted, drunk or swallowed amphetamine (table 2).

\section{Sexual behaviour}

Nine-tenths $(89 \%, 350 / 395)$ reported having anal or vaginal sex in the preceding year, and $9.1 \%(36 / 395)$ had $\geq 10$ partners (table 1 ). Considering just female partners, $20 \%(80 / 395)$ of respondents had $\geq 5$ partners. Thirteen $(3.3 \%)$ reported $\geq 1$ male sexual partner during the preceding year (table 1). Those reporting male sexual partners were older than those who did not (median age 38 years, IQR 12; and 28 years, IQR 11, respectively). Those reporting male sexual partners were also more likely to have ever injected a psychoactive drug $(23 \%(3 / 13)$ vs $4.2 \% \quad(16 / 382), p=0.020)$, more likely to report snorting, drinking or swallowing amphetamine during the last year $(46 \% \quad(6 / 13)$ vs $11 \%$ (41/382), $\mathrm{p}=0.002)$, and a higher proportion reported snorting cocaine, but this was not significant $(62 \%$ (8/ 13) vs $45 \%(173 / 382), \mathrm{p}=0.248)$. Those reporting male sexual partners were also more likely to report having ever shared a needle/syringe or vial $(25 \%$ (4/13) vs $8.1 \%(31 / 382), \mathrm{p}=0.021)$. A higher proportion of those reporting male sexual partners reported always using condoms during the last year, but this difference was not significant $(38 \% \quad(5 / 13)$ vs $19 \% \quad(73 / 382), \mathrm{p}=0.146)$ There were no differences in the types of IPED used, nor in their routes of administration, between those reporting male partners and those not. 
Table 1 Characteristics of male injectors of the IPEDs sampled

\begin{tabular}{|c|c|c|c|}
\hline \multicolumn{2}{|l|}{ Characteristic } & & \multirow[t]{2}{*}{$\mathbf{n}$} \\
\hline \multicolumn{3}{|l|}{ Demographic } & \\
\hline \multirow[t]{5}{*}{ Age, years } & Under25 & $27 \%$ & 106 \\
\hline & 25-34 & $34 \%$ & 134 \\
\hline & 35 and over & $27 \%$ & 107 \\
\hline & Median (IQR) & \multicolumn{2}{|c|}{28 (13) } \\
\hline & Not reported & $12 \%$ & 48 \\
\hline Had ever been in prison & & $16 \%$ & 63 \\
\hline \multicolumn{4}{|l|}{ Health service use } \\
\hline \multicolumn{2}{|l|}{ Had ever used a Needle and Syringe Programme } & $75 \%$ & 298 \\
\hline \multicolumn{2}{|l|}{ Had seen a general practitioner in the last year about their health } & $45 \%$ & 178 \\
\hline \multirow{2}{*}{\multicolumn{2}{|c|}{ Had you got advice at an Accident \& Emergency / Walk-in in the last year }} & $16 \%$ & 64 \\
\hline & & $28 \%$ & 111 \\
\hline \multicolumn{2}{|c|}{ Had sought advice from a sexual health / sexually transmitted infections clinic in the last year } & $17 \%$ & 68 \\
\hline \multicolumn{2}{|l|}{ Had been vaccinated against hepatitis $B$} & $23 \%$ & 90 \\
\hline \multicolumn{2}{|l|}{ Had had a blood test for hepatitis C } & $22 \%$ & 85 \\
\hline Had had a blood test for HIV & & $31 \%$ & 122 \\
\hline Symptom of injury or infection at injection site & & & \\
\hline \multicolumn{2}{|l|}{ Had ever had redness at an injection site } & $43 \%$ & 168 \\
\hline \multirow{2}{*}{\multicolumn{2}{|c|}{$\begin{array}{l}\text { Had ever had an injection site abscess/sore/open wound } \\
\text { Image and performance enhancina drua use last vear }\end{array}$}} & $6.80 \%$ & 27 \\
\hline & \multicolumn{3}{|c|}{ Image and performance enhancing drug use, last year } \\
\hline \multirow[t]{3}{*}{ Years since first used an image and performance enhancing drug } & $0-4$ & $36 \%$ & 141 \\
\hline & $\begin{array}{l}5+ \\
\text { Median }(I Q R)\end{array}$ & \multicolumn{2}{|c|}{$4(8)$} \\
\hline & Not reported & $32 \%$ & 126 \\
\hline \multicolumn{2}{|l|}{ Oral anabolic steroids } & $57 \%$ & 226 \\
\hline Oral anti-oestrogens & & $23 \%$ & 92 \\
\hline Oral clenbuterol & & $15 \%$ & 60 \\
\hline Oral ephedrine & & $20 \%$ & 78 \\
\hline Oral thyroid hormones & & $9 \%$ & 37 \\
\hline Oral phosphodiesterase type 5 inhibitor (PDE5i; "Viagra/Calias”) & & $6.6 \%$ & 26 \\
\hline Oral other image and performance enhancing drug (inc. Diuretics, & & $12 \%$ & 46 \\
\hline 2,4-dinitrophenol and Pro/designer) & & & \\
\hline Injected anabolic steroids & & $86 \%$ & 340 \\
\hline Injected growth hormone & & $32 \%$ & 128 \\
\hline Injected human chorionic gonadotropin (hCG) & & $16 \%$ & 62 \\
\hline Injected insulin injected & & $5.6 \%$ & 22 \\
\hline Injected melanotan & & $8.6 \%$ & 34 \\
\hline $\begin{array}{l}\text { Injected other image and performance enhancing drug (inc. ethryof } \\
\text { insulin-like growth factor } 1 \text { and nalbuphine hydrochloride) }\end{array}$ & & $5.1 \%$ & 20 \\
\hline Use of other illicit drugs & & & \\
\hline Ever injected illicit drug other than an image and performance enha & ug. & $4.8 \%$ & 19 \\
\hline Snorted cocaine in the last year & & $46 \%$ & 181 \\
\hline Snorted, drunk or swallowed amphetamine in last year & & $12 \%$ & 47 \\
\hline Injecting practice & & & \\
\hline Who usually injected you, last year? & Someone else & $17 \%$ & 68 \\
\hline & Myself & $74 \%$ & 294 \\
\hline & Not reported & $8.4 \%$ & 33 \\
\hline Intramuscular injection in the last year & & $88 \%$ & 346 \\
\hline Subcutaneous injection in the last year & & $39 \%$ & 154 \\
\hline Ever shared needle, syringe or vial & & $8.9 \%$ & 35 \\
\hline Sexual behaviour & & & \\
\hline Number of sexual partners last year & One & $38 \%$ & 152 \\
\hline & Two or more & $47 \%$ & 187 \\
\hline & Not reported/no sex & $14 \%$ & 56 \\
\hline Gender of sexual partners last year & Male partner(s) & $3.3 \%$ & 13 \\
\hline & No male partners & $82 \%$ & 323 \\
\hline & Not reported/no sex & $15 \%$ & 59 \\
\hline Always condom (anal/vaginal sex) or no sex last year & & $20 \%$ & 78 \\
\hline
\end{tabular}


Table 2 Factors associated with risk behaviours among the IPEDs sampled

\begin{tabular}{|c|c|c|c|c|c|c|c|c|c|c|c|}
\hline \multirow{2}{*}{$\begin{array}{l}\text { Ever shared a needle, syringe or vial } \\
\text { Number of sexual partners in the last year }\end{array}$} & \multirow{2}{*}{$\begin{array}{l}\text { Total } \\
395\end{array}$} & \multicolumn{2}{|l|}{ Yes } & \multicolumn{4}{|c|}{$\begin{array}{l}\text { Unadjusted odds } \\
\text { ratio with } 95 \% \mathrm{Cl}\end{array}$} & \multicolumn{4}{|c|}{$\begin{array}{l}\text { Adjusted odds ratio } \\
\text { with } 95 \% \mathrm{Cl}\end{array}$} \\
\hline & & (3) & 0.510 & & & & & & & & \\
\hline One & 152 & 8 & $5.3 \%$ & 0.3 & 0.12 & - & 0.94 & * & & & \\
\hline Two or more & 187 & 19 & $10 \%$ & 0.7 & 0.28 & - & 1.6 & & & & \\
\hline Not reported/no sex & 56 & 8 & $14 \%$ & 1.0 & & & & & & & \\
\hline Pearson $\chi^{2}$ test & $p=$ & 0.088 & & & & & & & & & \\
\hline \multicolumn{12}{|l|}{ Gender of sexual partners in the last year } \\
\hline Male partner(s) & 13 & 4 & $31 \%$ & 5.5 & 1.6 & - & 19 & * & & & \\
\hline No male partners & 323 & 24 & $7.4 \%$ & 1.0 & & & & & & & \\
\hline Not reported/no sex & 59 & 7 & $12 \%$ & 1.7 & 0.69 & - & 4.1 & & & & \\
\hline Pearson $\chi^{2}$ test & $p=$ & 0.010 & & & & & & & & & \\
\hline \multicolumn{12}{|l|}{ Injected illicit drugs other than IPED } \\
\hline Yes & 19 & 7 & $37 \%$ & 7.2 & 2.6 & - & 20 & 6.3 & 2.1 & - & 19 \\
\hline No/not reported & 376 & 28 & $7.4 \%$ & 1.0 & & & & 1.0 & & & \\
\hline Fisher's exact test & $p=$ & 0.001 & & & & & & & & & \\
\hline \multicolumn{12}{|c|}{ Have you got advice from a SH/STI clinic in the last year? } \\
\hline Yes & 68 & 11 & $16 \%$ & 2.4 & 1.1 & - & 5.2 & 2.2 & 1.0 & - & 5.1 \\
\hline No/not sure & 327 & 24 & $7.3 \%$ & 1.0 & & & & 1.0 & & & \\
\hline Pearson $\chi^{2}$ test & $p=$ & 0.020 & & & & & & & & & \\
\hline \multicolumn{12}{|l|}{ Injected growth hormone (as IPED) } \\
\hline Yes & 128 & 18 & $14 \%$ & 2.4 & 1.2 & - & 4.8 & * & & & \\
\hline No & 267 & 17 & $6.4 \%$ & 1.0 & & & & & & & \\
\hline Pearson $\chi^{2}$ test & $p=$ & 0.012 & & & & & & & & & \\
\hline \multicolumn{12}{|l|}{ Injected Insulin (as IPED) } \\
\hline Yes & 22 & 5 & $23 \%$ & 3.4 & 1.2 & - & 9.8 & * & & & \\
\hline No & 373 & 30 & $8.0 \%$ & 1.0 & & & & & & & \\
\hline Fisher's exact test & $p=$ & 0.035 & & & & & & & & & \\
\hline \multicolumn{12}{|l|}{ Subcutaneous injection in the last year? } \\
\hline Yes & 154 & 21 & $14 \%$ & 2.6 & 1.3 & - & 5.2 & 3.0 & 1.4 & - & 6.5 \\
\hline No/not sure & 241 & 14 & $6 \%$ & 1.0 & & & & 1.0 & & & \\
\hline Pearson $\chi^{2}$ test & $p=$ & 0.008 & & & & & & & & & \\
\hline \multicolumn{12}{|l|}{ Snorted cocaine in the last year? } \\
\hline Yes & 181 & 22 & $12 \%$ & 2.1 & 1.0 & - & 4.4 & * & & & \\
\hline No & 214 & 13 & $6.1 \%$ & 1.0 & & & & & & & \\
\hline Pearson $\chi^{2}$ test & $p=$ & 0.034 & & & & & & & & & \\
\hline \multicolumn{12}{|c|}{ Snorted, drunk or swallowed amphetamine in the last year? } \\
\hline Yes & 47 & 11 & $23 \%$ & 4.1 & 1.9 & - & 9.1 & 4.1 & 1.7 & - & 9.8 \\
\hline No & 348 & 24 & $6.9 \%$ & 1.0 & & & & 1.0 & & & \\
\hline Pearson $\chi^{2}$ test & $p=$ & 0.0002 & & & & & & & & & \\
\hline Always used condom for anal/vaginal sex & 350 & 48 & $14 \%$ & & & & & & & & \\
\hline \multicolumn{12}{|l|}{ Gender of sexual partners in the last year } \\
\hline Male partner(s) & 13 & 5 & $38 \%$ & 8.1 & 0.8 & - & 83 & 14 & 1.3 & - & 155 \\
\hline No male partners & 323 & 42 & $13 \%$ & 1.9 & 0.25 & - & 15 & 2.8 & 0.35 & - & 22 \\
\hline Not reported & 14 & 1 & $7.1 \%$ & 1.0 & & & & 1.0 & & & \\
\hline Pearson $\chi^{2}$ test & $p=$ & 0.025 & & & & & & & & & \\
\hline \multicolumn{12}{|c|}{ Have you ever had a blood test for hepatitis C? } \\
\hline Yes & 82 & 17 & $21 \%$ & 3.2 & 1.1 & - & 9 & * & & & \\
\hline No & 201 & 26 & $13 \%$ & 1.8 & 0.68 & - & 5.0 & & & & \\
\hline Not sure & 67 & 5 & $7.5 \%$ & 1.0 & & & & & & & \\
\hline Pearson $\chi^{2}$ test & $p=$ & 0.057 & & & & & & & & & \\
\hline \multicolumn{12}{|l|}{ Injected anabolic steroids } \\
\hline Yes & 304 & 46 & $15 \%$ & 3.9 & 0.92 & - & 17 & 4.2 & 0.96 & - & 18 \\
\hline No & 46 & 2 & $4.3 \%$ & 1.0 & & & & 1.0 & & & \\
\hline Pearson $\chi^{2}$ test & $p=$ & 0.048 & & & & & & & & & \\
\hline
\end{tabular}




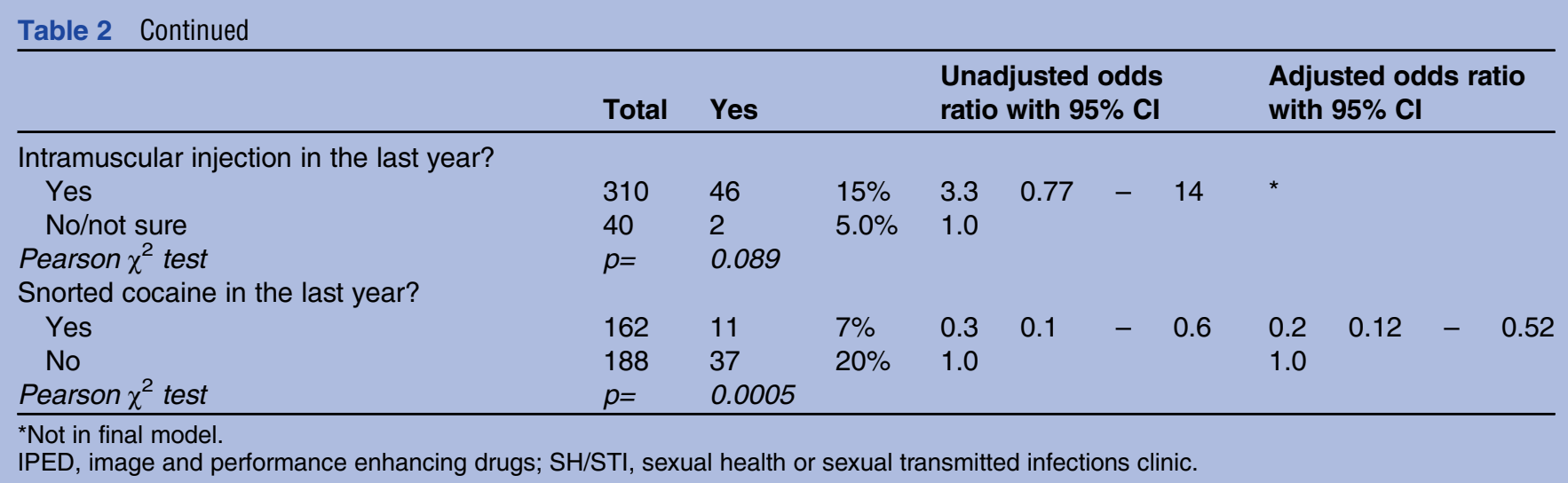

Among those who reported sex during the preceding year, $14 \%$ (95\% CI $11 \%$ to $18 \%, 48 / 350$ ) had always used condoms. Factors associated with condom use are given in table 2. Always using condoms among those who had had sex during the preceding year was associated in the multivariable analysis with having had a male sexual partner and having not snorted cocaine (table 2).

\section{BBV prevalence}

Overall, $1.5 \%$ (95\% CI $0.7 \%$ to $3.3 \%$; $n=6$ ) had anti-HIV, $8.8 \%$ (95\% CI $6.4 \%$ to $12 \%$ ) had ever been infected with hepatitis B (26 anti-HBc positive, adjusted for test sensitivity of 0.75 ) and $5.5 \%$ (95\% CI $3.7 \%$ to $8.2 \%$ ) with hepatitis C (20 anti-HCV positive, adjusted for test sensitivity of 0.92). Covariates associated with anti-HIV, anti-HBc or anti-HCV positivity are given in table 3 . In the multivariable analysis, anti-HIV positivity was associated with having male sexual partners in the preceding year, ever having an abscess/sore/open wound at the injection site, and having sought advice from an SH/STI clinic in the preceding year (table 3). Having anti-HBc was associated in the multivariable analysis with having obtained advice from an SH/STI clinic and having not injected oneself subcutaneously in the preceding year (table 3). Anti-HCV positivity was associated with having ever injected a psychoactive drug and having taken a phosphodiesterase type 5 inhibitor (PDE5i) in the preceding year in the multivariable analysis (table 3).

After excluding those who reported either sex with men or having ever injected a psychoactive drug, $0.8 \%$ had anti-HIV (95\% CI $0.28 \%$ to $2.4 \%, 3 / 366$ ), $8.0 \%$ anti-HBc (95\% CI $5.6 \%$ to $11 \%$, adjusted for test sensitivity, 22/366) and $4.7 \%$ anti-HCV (95\% CI $2.9 \%$ to $7.3 \%$, adjusted for test sensitivity, $16 / 366$ ), with $10 \%$ (95\% CI $7.7 \%$ to $14 \%$, 38/366) having one or more of these three markers. In this group, having anti-HIV was found to be associated only with ever having had an abscess/wound at an injection site $(8 \%(2 / 25)$ vs $0.29 \%(1 / 341)$ for those who had not, $\mathrm{p}=0.013)$, and having anti-HBc was only associated with having sought advice from an $\mathrm{SH} / \mathrm{STI}$ clinic in the preceding year $(16 \%(9 / 56)$ vs $4.2 \%(13 / 310)$ for those who had not, $p=0.002)$. The use of three types of IPEDs was associated with having anti-HCV: having taken a PDE5i
(21\% (5/24) vs $3.2 \%(11 / 342)$ for those who had not, $\mathrm{p}=0.002)$; having injected insulin as an IPED $(18 \%(3 / 17)$ vs $3.7 \%(13 / 349)$ for those who had not, $\mathrm{p}=0.032)$; and having injected a less commonly used IPED (17\% (3/18) vs $3.7 \%(13 / 348)$ for those who had not, $\mathrm{p}=0.037)$.

In total, $47(12 \%, 95 \%$ CI $9.1 \%$ to $15 \%)$ were positive for one or more of the anti-HIV, anti-HBc and anti-HCV, with 43 having just one of these markers and four having two or more of these markers. Two had anti-HBc and anti-HCV, one of these reported injected psychoactive drugs, and neither reported having had sex with men. One, who reported sex with men and injecting psychoactive drugs, had anti-HIV and anti-HBc; the remaining participant had all three markers and did not report either sex with men or injecting psychoactive drugs.

Uptake of interventions related to the three BBV infections was poor. Overall, only $23 \%$ reported receiving a dose of $\mathrm{HBV}$ vaccine, $31 \%$ ever having a diagnostic HIV test and 22\% having an HCV test (table 1).

\section{DISCUSSION}

IPED injectors are at risk of infection with HIV as well as other BBVs. This is the first prevalence study to have found HIV among IPED injectors, with the prevalence at $1.5 \%$, similar to that found among injectors of psychoactive drugs in England and Wales $\left(1.2 \%, 2011^{40}\right)$. However, anti-HBc and anti-HCV-at $8.8 \%$ and $5.5 \%$, respectively-are lower than among psychoactive drug injectors $\left(16 \%\right.$ and $43 \%$, respectively, $\left.2011^{40}\right)$. The prevalence of all three BBVs in this sample would appear to be higher than that found in the general UK population. ${ }^{41}{ }^{42}$ Once those who reported either sex with men or injecting psychoactive drugs were excluded, $10 \%$ had been infected with one or more of HIV, hepatitis $\mathrm{B}$ and $\mathrm{C}$.

It is important to consider the limitations of this study. The comparative rarity, marginalisation and illicit nature of injecting drug use impede the construction of a sampling frame, making the representativeness of our sample impossible to measure. This study used an established methodology for recruiting PWID through specialist services $^{26}{ }^{27}$; however, the robustness of this 
Table 3 Factors associated the blood-borne virus infections among the IPEDs sampled

\begin{tabular}{|c|c|c|c|c|c|c|c|c|c|c|c|}
\hline \multirow[b]{2}{*}{ HIV } & \multirow{2}{*}{$\begin{array}{l}\text { Total } \\
395\end{array}$} & \multicolumn{2}{|c|}{ Positive } & \multicolumn{4}{|c|}{$\begin{array}{l}\text { Unadjusted odds } \\
\text { ratio with } 95 \% \mathrm{Cl}\end{array}$} & \multicolumn{4}{|c|}{$\begin{array}{l}\text { Adjusted odds ratio } \\
\text { with } 95 \% \mathrm{Cl}\end{array}$} \\
\hline & & 6 & $1.5 \%$ & & & & & & & & \\
\hline \multicolumn{12}{|l|}{ Age, years* } \\
\hline Aged $<35$ or age unknown & 287 & 1 & $0.3 \%$ & 1.0 & & & & * & & & \\
\hline Aged 35 or over & 102 & 5 & $4.9 \%$ & 14 & 1.62 & - & 122 & & & & \\
\hline Fisher's exact test & $\mathrm{p}=$ & 0.006 & & & & & & & & & \\
\hline \multicolumn{12}{|l|}{ Gender of sexual partners in the last year* } \\
\hline Male sexual partner & 13 & 3 & $23 \%$ & 38 & 6.79 & - & 211 & * & & & \\
\hline No male partner/no sex & 382 & 3 & $0.8 \%$ & 1 & & & & & & & \\
\hline Fisher's exact test & $\mathrm{p}=$ & 0.001 & & & & & & & & & \\
\hline \multicolumn{12}{|c|}{ Gender of sexual partners in the last year and age (in years) ${ }^{*}$} \\
\hline Male sexual partner & 13 & 3 & $23 \%$ & 85 & 8.13 & - & 893 & 79 & 4.29 & - & 1450 \\
\hline No Male partners, aged $<35$ or age not reported & 285 & 1 & $0.4 \%$ & 1.0 & & & & 1.0 & & & \\
\hline No male partners, aged 35 or over & 97 & 2 & $2.1 \%$ & 6 & 0.54 & - & 67 & 9 & 0.59 & - & 135 \\
\hline Pearson $\chi^{2}$ test & $\mathrm{p}<$ & 0.001 & & & & & & & & & \\
\hline \multicolumn{12}{|l|}{ Injected illicit drugs other than IPED } \\
\hline Yes & 19 & 2 & $11 \%$ & 11 & 1.87 & - & 63.95 & $\dagger$ & & & \\
\hline No/not reported & 376 & 4 & $1.1 \%$ & 1 & & & & & & & \\
\hline Fisher's exact test & $p=$ & 0.029 & & & & & & & & & \\
\hline \multicolumn{12}{|c|}{ Ever had an abscess/sore/open wound at the injection site? } \\
\hline Yes & 27 & 2 & $7.4 \%$ & 7.3 & 1.27 & - & 41.69 & 77 & 3.27 & - & 1795 \\
\hline No/not sure & 368 & 4 & $1.1 \%$ & 1.0 & & & & 1.0 & & & \\
\hline Fisher's exact test & $p=$ & 0.057 & & & & & & & & & \\
\hline \multicolumn{12}{|c|}{ Taken or used any prescribed medication in the last year? } \\
\hline Yes & 111 & 5 & $4.5 \%$ & 13 & 1.54 & - & 116 & $\dagger$ & & & \\
\hline No/not sure & 284 & 1 & $0.4 \%$ & 1 & & & & & & & \\
\hline Fisher's exact test & $\mathrm{p}=$ & 0.008 & & & & & & & & & \\
\hline \multicolumn{12}{|c|}{ Have you got advice from a SH/STI clinic in the last year? } \\
\hline Yes & 68 & 4 & $5.9 \%$ & 10 & 1.82 & - & 56.6 & 24 & 1.03 & - & 542 \\
\hline No/not sure & 327 & 2 & $0.6 \%$ & 1 & & & & 1.0 & & & \\
\hline Fisher's exact test & $\mathrm{p}=$ & 0.009 & & & & & & & & & \\
\hline \multicolumn{12}{|l|}{ Have you ever been vaccinated against hepatitis $B ?$} \\
\hline Yes & 90 & 4 & $4.4 \%$ & 7.0 & 1.27 & - & 39.1 & $\dagger$ & & & \\
\hline No/not sure & 305 & 2 & $0.7 \%$ & 1.0 & & & & & & & \\
\hline Fisher's exact test & $\mathrm{p}=$ & 0.026 & & & & & & & & & \\
\hline \multicolumn{12}{|l|}{ Have you ever had a blood test for hepatitis C? } \\
\hline Yes & 81 & 4 & $4.7 \%$ & 7.6 & 1.37 & - & 42.3 & $\dagger$ & & & \\
\hline No/not sure & 308 & 2 & $0.9 \%$ & 1.0 & & & & & & & \\
\hline Fisher's exact test & $p=$ & 0.021 & & & & & & & & & \\
\hline \multicolumn{12}{|l|}{ Have you ever had a blood test for HIV? } \\
\hline Yes & 122 & 4 & $3.3 \%$ & 4.6 & 0.83 & - & 25.4 & $\dagger$ & & & \\
\hline No/not sure & 273 & 2 & $0.7 \%$ & 1.0 & & & & & & & \\
\hline Fisher's exact test & $\mathrm{p}=$ & 0.076 & & & & & & & & & \\
\hline Ever shared a needle, syringe or vial? & & & & & & & & & & & \\
\hline Yes & 35 & 2 & $5.7 \%$ & 5.4 & 0.95 & - & 30.6 & $\dagger$ & & & \\
\hline No/not sure & 360 & 4 & $1.1 \%$ & 1.0 & & & & & & & \\
\hline Fisher's exact test & $\mathrm{p}=$ & 0.091 & & & & & & & & & \\
\hline Anti-HBc & 395 & 26 & $6.6 \%$ & & & & & & & & \\
\hline Have you got advice from a SH/STI clinic in the las & year? & & & & & & & & & & \\
\hline Yes & 68 & 10 & $14.7 \%$ & 1.0 & & & & 1.0 & & & \\
\hline No/not sure & 327 & 16 & $4.9 \%$ & 3.4 & 1.4 & - & 7.7 & 3.8 & 1.6 & - & 8.9 \\
\hline Fisher's exact test & $\mathrm{p}=$ & 0.006 & & & & & & & & & \\
\hline Subcutaneous injection in the last year? & & & & & & & & & & & \\
\hline Yes & 154 & 6 & $3.9 \%$ & 1.0 & & & & 1.0 & & & \\
\hline No/not sure & 241 & 20 & $8.3 \%$ & 2.2 & 0.88 & - & 5.7 & 2.6 & 0.99 & - & 6.7 \\
\hline Pearson $\chi^{2}$ test & $\mathrm{p}=$ & 0.085 & & & & & & & & & \\
\hline
\end{tabular}


Table 3 Continued

\begin{tabular}{|c|c|c|c|c|c|c|c|c|c|c|c|}
\hline \multirow[b]{2}{*}{ Anti-HCV } & \multirow{2}{*}{$\begin{array}{l}\text { Total } \\
395\end{array}$} & \multicolumn{2}{|c|}{ Positive } & \multicolumn{4}{|c|}{$\begin{array}{l}\text { Unadjusted odds } \\
\text { ratio with } 95 \% \mathrm{CI}\end{array}$} & \multicolumn{4}{|c|}{$\begin{array}{l}\text { Adjusted odds ratio } \\
\text { with } 95 \% \mathrm{Cl}\end{array}$} \\
\hline & & 20 & $5.1 \%$ & & & & & & & & \\
\hline \multicolumn{12}{|l|}{ Age, years } \\
\hline Under 25 & 106 & 4 & $3.8 \%$ & 1.0 & & & & $\dagger$ & & & \\
\hline 25-34 & 134 & 3 & $2.2 \%$ & 0.58 & 0.13 & - & 2.7 & & & & \\
\hline 35 and over & 107 & 10 & $9.3 \%$ & 2.6 & 0.80 & - & 8.7 & & & & \\
\hline Not Reported & 48 & 3 & $6.3 \%$ & 1.7 & 0.37 & - & 7.9 & & & & \\
\hline Pearson $\chi^{2}$ test & $p=$ & 0.078 & & & & & & & & & \\
\hline \multicolumn{12}{|c|}{ Injected illicit drugs other than IPED } \\
\hline Yes & 19 & 3 & $15.8 \%$ & 4.0 & 1.1 & - & 15 & 4.4 & 1.1 & - & 17.2 \\
\hline No/not Sure & 376 & 17 & $4.5 \%$ & 1.0 & & & & 1.0 & & & \\
\hline Fisher's exact test & $p=$ & 0.064 & & & & & & & & & \\
\hline \multicolumn{12}{|c|}{ Taken or used any prescribed medication in the last year? } \\
\hline Yes & 111 & 10 & $9.0 \%$ & 2.7 & 1.1 & - & 7 & $\dagger$ & & & \\
\hline No/not sure & 284 & 10 & $3.5 \%$ & 1.0 & & & & & & & \\
\hline Pearson $\chi^{2}$ test & $p=$ & 0.025 & & & & & & & & & \\
\hline \multicolumn{12}{|c|}{ Have you ever had a blood test for hepatitis $C$ ? } \\
\hline Yes & 85 & 8 & $9.4 \%$ & 1.7 & 0.55 & - & 5.6 & $\dagger$ & & & \\
\hline No & 221 & 7 & $3.2 \%$ & 0.5 & 0.17 & - & 1.8 & & & & \\
\hline Not sure & 89 & 5 & $5.6 \%$ & 1.0 & & & & & & & \\
\hline Pearson $\chi^{2}$ test & $p=$ & 0.080 & & & & & & & & & \\
\hline \multicolumn{12}{|c|}{ Taken PDE5i: Viagra/cialis } \\
\hline Yes & 26 & 5 & $19 \%$ & 5.6 & 1.9 & - & 17 & 6.0 & 1.9 & - & 18 \\
\hline No & 369 & 15 & $4.1 \%$ & 1.0 & & & & 1.0 & & & \\
\hline Fisher's exact test & $p=$ & 0.007 & & & & & & & & & \\
\hline \multicolumn{12}{|c|}{ Injected insulin (as IPED) } \\
\hline Yes & 22 & 4 & $18 \%$ & 5.0 & 1.5 & - & 16 & $\dagger$ & & & \\
\hline No & 373 & 16 & $4.3 \%$ & 1.0 & & & & & & & \\
\hline Fisher's exact test & $p=$ & 0.019 & & & & & & & & & \\
\hline \multicolumn{12}{|c|}{ Other injected IPED (inc. EPO, IGF-1 and Nubain) } \\
\hline Yes & 20 & 3 & $15 \%$ & 3.7 & 0.99 & - & 14 & $\dagger$ & & & \\
\hline No & 375 & 17 & $4.5 \%$ & 1.0 & & & & & & & \\
\hline Fisher's exact test & $p=$ & 0.073 & & & & & & & & & \\
\hline \multicolumn{12}{|c|}{ Ever shared a needle, syringe or vial? } \\
\hline Yes & 35 & 4 & $11 \%$ & 2.8 & 0.87 & - & 8.8 & $\dagger$ & & & \\
\hline No/not sure & 360 & 16 & $4 \%$ & 1.0 & & & & & & & \\
\hline Fisher's exact test & $p=$ & 0.090 & & & & & & & & & \\
\hline
\end{tabular}

approach for IPED injectors is unknown and cannot currently be assessed due to the very limited knowledge on the size and nature of this group. ${ }^{35}$ The use of NSPs to access this group was a pragmatic approach; communitybased recruitment approaches, such as Respondent Driven Sampling and Time-Location Sampling, that are often advocated for hard to reach populations ${ }^{43}$ are possible alternatives. However, these are likely to be difficult to implement with this group due to the diversity of the drugs used, the clandestine and close-knit nature of this group and because drug use usually takes place in private settings (such as homes or gyms). ${ }^{35}$ The findings here also rely on self-reported behaviours-though their reliability has not been assessed among IPED users, these have been found to be reliable for psychoactive drug injectors ${ }^{44}{ }^{45}$ _and infection with BBVs has been determined by laboratory-based biological data from the testing of oral-fluid samples. While oral-fluid testing is highly sensitive for anti-HIV, the sensitivity is reduced for anti-HCV and anti-HBc. ${ }^{39}$ While this is the largest study of BBVs in this population, the sample size still restricts its power, and consequently caution is needed when attempting to generalise these findings to the wider population of IPED injectors.

The levels of HIV and anti-HBc are higher than in the only previous UK study to measure these in IPED 
injectors. Undertaken $>10$ years ago using a similar methodology, this found no HIV and an anti-HBc prevalence of $2 \% ;^{20}$ suggesting that the prevalence of these infections among IPED injectors might have increased over time. Exposure to BBVs among IPED injectors appears to be associated with sexual risks and the injection of psychoactive drugs; although injecting psychoactive drugs is rare among IPED injectors, unprotected sex with multiple partners is common. The sharing of injecting equipment or drug vials among IPED injectors at $8.9 \%$ is much less common than among injectors of psychoactive drugs (in 2011, 37\% of psychoactive drug injectors reported recently sharing injecting equipment ${ }^{40}$ ). Though exposure was not associated with sharing in the multivariate analyses in this study, BBV transmission through IPED injection cannot be excluded as this study may have lacked sufficient power to detect this.

The associations between having HIV and the use of SH/STI clinics and having male sexual partners suggest that HIV transmission among IPED injectors might be related to sexual activity. This association may reflect AS use by some HIV positive gay and bisexual men to mask the longer-term effects of HIV infection. ${ }^{35}$ The association with having an abscess/wound at the injection site probably reflects the greater vulnerability of PWID with HIV to injection-related bacterial infections. ${ }^{46}{ }^{47}$ The association between exposure to $\mathrm{HBV}$ and having obtained advice from an SH/STI clinic is again suggestive of a role for sexual risk in infection, particularly as sexual transmission is the main route by which $\mathrm{HBV}$ is now acquired within the UK. ${ }^{48}$ The association between having anti-HBc and not injecting subcutaneously suggests that certain patterns of IPED use might be related to increased risk, as some IPEDs are only injected subcutaneously and others only intramuscularly, and many users take several types. ${ }^{3} 8$ 12-14 Exposure to HCV, however, would appear to be associated with the injection of psychoactive drugs, an association that has been previously noted ${ }^{6}$; this finding might reflect more frequent injecting in this subgroup. Sexual activity may also play a role, assuming that the use of PDE5i is related to improving or maintaining sexual performance. These associations all require further investigation.

The level sharing found here was in line with that in previous studies of injecting risk among IPED users. $^{20}$ 28-30 323335 The association between sharing and subcutaneous injection suggests that sharing-like HBV exposure-may be associated with certain patterns of IPED use. As in previous studies of IPED injectors, sexual activity was common and condom use was poor. ${ }^{20} 2834$ Condom use was higher among those with male sexual partners and lower among those who reported snorting cocaine. The more frequent use of condoms by gay and bisexual men probably reflects an awareness of their increased HIV risk. ${ }^{42}$ The association with cocaine use might possibly be related to its use as a sexual stimulant, with this possibly related to attempts to counteract the reduced libido experienced on discontinuation of AS use or in the periods between courses of AS use ('off-cycles'). ${ }^{14}$ In part, this effect may be as a result of the decrease in endogenous testosterone production, ${ }^{49}$ which is why IPED users self-treat with human chorionic gonadotrophin in an attempt to stimulate endogenous production, with PDE5i used to symptomatically treat erectile dysfunction. ${ }^{514} 50$ Increased libido following AS administration is also reported by users, ${ }^{14} 333451$ with similar effects being reported following the use of drugs such as melanotan-II. ${ }^{12}$

Associations were found between psychoactive drug use and sharing and poor condom use. IPED users who also use psychoactive drugs may be a higher risk-or perhaps less risk averse-subgroup. While this needs further investigation, it suggests-considering the substantial levels of psychoactive drug use found here and in previous studies ${ }^{6} 8283536$-that those using IPED and psychoactive drugs should be an important target group for harm reduction interventions.

This study indicates that those providing services to PWID-particularly NSPs, outreach services and general practitioners-should be alert to the needs of those who use IPEDs. In particular, they need to be aware of the range of drugs that may be used by this group and of the associated injecting practices, as these differ from those of psychoactive drug injectors. Considering the BBV prevalence and levels of risk found, specialist services for PWID need to engage with IPED users and ensure that they have access to appropriate injecting equipment and targeted harm reduction advice. They should also ensure that this group has access to testing for BBVs, hepatitis B vaccinations, sexual health services and condoms.

Our findings suggest that sexual risk and the use, and particularly the injection, of psychoactive drugs are possibly the most important factors associated with BBV transmission among IPED injectors. The transmission of HIV and other BBVs through the injecting of IPED cannot be excluded, and this is certainly possible as equipment sharing does occur. However, the participants in this study were largely recruited through NSPs providing injecting equipment and advice. IPED injectors not in contact with NSPs may have a different risk profile and infection risk. Even so, our findings suggest the need for targeted interventions to address sexual health needs, psychoactive drug use and the injection practices among IPED injectors. Considering the limitations of this study, a larger study recruiting from a wider range of settings and collecting dried-blood samples is needed to more fully examine prevalence and, in particular, the associated risk factors and thus the role of IPED injection in transmission of HIV and other BBVs.

\section{Author affiliations}

${ }^{1}$ Public Health England, London, UK

${ }^{2}$ Centre for Research on Drugs and Health Behaviour, London School of Hygiene \& Tropical Medicine, London, UK

${ }^{3}$ Centre for Public Health, Liverpool John Moores University, Liverpool, UK

${ }^{4}$ European Monitoring Centre for Drugs and Drug Addiction, Lisbon, Portugal

${ }^{5}$ Public Health Wales, Temple of Peace \& Health, Cathays Park, Cardiff, UK

${ }^{6}$ Department of Public Health, Aarhus University, Aarhus, Denmark 
Acknowledgements The authors are grateful to all the people who injected image and performance enhancing drugs and took part in the survey, as well as to the various services across England and Wales who assisted with their recruitment. The authors would like to thank the support staff who worked on the survey and those who undertook the laboratory work. The survey was undertaken by the Health Protection Agency (now part of Public Health England) which is funded through the Department of Health.

Contributors MEB, AK, JM, AM and VH developed the modified questionnaire used with the IPED injectors. AM undertook the day-to-day co-ordination of the survey of IPED injectors, with support from MEB and VH. The ongoing monitoring survey was managed by $\mathrm{VH}$ and FN. Development of the laboratory tests and processes employed was led by JP, who managed their application to this study. All authors contributed to the writing of the paper, with writing and analyses led by VH.

Funding This research received no specific grant from any funding agency in the public, commercial or not-for-profit sectors.

\section{Competing interests None.}

Ethics approval London MREC.

Provenance and peer review Not commissioned; externally peer reviewed.

Data sharing statement No additional data are available.

Open Access This is an Open Access article distributed in accordance with the Creative Commons Attribution Non Commercial (CC BY-NC 3.0) license which permits others to distribute, remix, adapt, build upon this work noncommercially, and license their derivative works on different terms, provided the original work is properly cited and the use is non-commercial. See: http:// creativecommons.org/licenses/by-nc/3.0/

\section{REFERENCES}

1. Aceijas C, Stimson GV, Hickman M, et al. Global overview of injecting drug use and HIV infection among injecting drug users. AIDS 2004;18:2295-303.

2. Nelson PK, Mathers BM, Cowie B, et al. Global epidemiology of hepatitis $B$ and hepatitis $C$ in people who inject drugs: results of systematic reviews. Lancet 2011;378:571-83.

3. Evans-Brown M, McVeigh J, Perkins C, et al. Human enhancement drugs: the emerging challenges to public health. Liverpool: North West Public Health Observatory, 2012.

4. McVeigh J, Evans-Brown M, Bellis MA. Human enhancement drugs and the pursuit of perfection. Adicciones 2012;24:185-90.

5. Advisory Council on the Misuse of Drugs. Consideration of the anabolic steroids. Home Office, 2010.

6. Iversen J, Topp L, Wand $\mathrm{H}$, et al. Are people who inject performance and image-enhancing drugs an increasing population of Needle and Syringe Program attendees? Drug Alcohol Rev 2012;122(3): 195-200. doi:10.1111/j.1465-3362.2012.00499.x

7. Aitken C, Cheryl D, Kay S. Pumping iron, risking infection? Exposure to hepatitis $C$, hepatitis $B$ and HIV among anabolic-androgenic steroid injectors in Victoria, Australia. Drug Alcohol Depend 2002;65:303-8.

8. Larance B, Degenhardt L, Copeland J, et al. Injecting risk behaviour and related harm among men who use performance- and image-enhancing drugs. Drug Alcohol Rev 2008;27:679-86.

9. Christiansen AV. Testing citizens training recreationally in gyms. In McNamee MMøller V, eds. Doping and anti-doping policy in sport. Abingdon: Routledge, 2011:126-41.

10. Mulcahey MK, Schiller JR, Hulstyn MJ. Anabolic steroid use in adolescents: identification of those at risk and strategies for prevention. Phys Sportsmed 2010;38:105-13.

11. Castillo Castillo EM, Comstock RD. Prevalence of use of performance-enhancing substances among United States adolescents. Pediatr Clin North Am 2007;54:663-75.

12. Evans-Brown M, Dawson RT, Chandler M, et al. Use of melanotan I and II in the general population. BMJ 2009;338:b566.

13. Evans-Brown M, McVeigh J. Injecting human growth hormone as a performance-enhancing drug-perspectives from the United Kingdom. J Subst Use 2009;14:267-88.

14. Llewellyn W. William Llewellyn's anabolics. 10 edn. Jupiter, FL: Molecular Nutrition, 2010.

15. Marquis CP, Maffulli N. Anabolic steroid related abscess-a risk worth taking? Inj Extra 2006;37:451-4.
16. Gautschi OP, Zellweger R. Images in clinical medicine. Methicillin-resistant Staphylococcus aureus abscess after intramuscular steroid injection. N Engl J Med 2006;355:713.

17. Dunn F. Two cases of biceps injury in bodybuilders with initially misleading presentation. Emerg Med J 2002;19:461-2.

18. Al Al-Ismail K, Torreggiani WC, Munk PL, et al. Gluteal mass in bodybuilder: radiological depiction of a complication of anabolic steroid use. Eur Radiol 2002;12:1366-9.

19. Evans NA. Local complications of self administered anabolic steroid injections. Br J Sports Med 1997;31:349-50.

20. Crampin AC, Lamagni TL, Hope VD, et al. The risk of infection with HIV and hepatitis B in individuals who inject steroids in England and Wales. Epidemiol Infect 1998;121:381-6.

21. Day CA, Topp L, Iversen J, et al. Collaboration of Australian NSPs. Blood-borne virus prevalence and risk among steroid injectors: results from the Australian Needle and Syringe Program Survey. Drug Alcohol Rev 2008;27:559-61.

22. Henrion R, Mandelbrot L, Delfieu D. Contamination par le VIH a la suite dinjections danabolisants. Presse Med 1992;21:218.

23. Scott MJ, Scott MJ Jr. HIV infection associated with injections of anabolic steroids. JAMA 1989;262:207-8.

24. Rich JD, Dickinson BP, Merriman NA, et al. Hepatitis C virus infection related to anabolic-androgenic steroid injection in a recreational weight lifter. Am J Gastroenterol 1998;93:1598.

25. Sklarek HM, Mantovani RP, Erens E, et al. AIDS in a bodybuilder using anabolic steroids. N Engl J Med 1984;311:1701.

26. Hope VD, Judd A, Hickman M, et al. HIV prevalence among injecting drug users in England and Wales 1990 to 2003: evidence for increased transmission in recent years. AIDS 2005;19:1207-14.

27. Hope VD, Rogers PA, Jordan L, et al. Sustained increase in the sharing of needles and syringes among drug users in England and Wales. AIDS 2002;16:2494-6.

28. Korkia P, Stimson G. Anabolic steroid use in Great Britain: an exploratory investigation. Final report to the Department of Health for England, Scotland and Wales. The Centre for Research on Drugs and Health Behaviour. October 1993.

29. Lenehan P, Bellis MA, McVeigh J. A study of anabolic steroid use in the North West of England. J Perform Enhanc Drugs 1996;1:57-70.

30. Pates R, Barry C. Steroid use in Cardiff: a problem for whom? J Perform Enhanc Drugs 1996;1:92-7.

31. Burton C. Anabolic steroid use among the gym population in Clwyd. Pharm J 1996;256:557-9.

32. Midgley S, Heather N, Best D, et al. Risk behaviours for HIV and hepatitis infection among anabolic-androgenic steroid users. AIDS Care 2000;12:163-70.

33. Grace FM, Baker JS, Davies B. Anabolic androgenic steroid use in recreational gym users: a regional sample of the Mid-Glamorgan area. J Subst Use 2001;6:189-95.

34. Bolding G, Sherr L, Maguire M, et al. HIV risk behaviours among gay men who use anabolic steroids. Addiction 1999;94:1829-35.

35. Bolding G, Sherr L, Elford J. Use of anabolic steroids and associated health risks among gay men attending London gyms. Addiction 2002;97:195-203.

36. Ip EJ, Barnett MJ, Tenerowicz MJ, et al. The anabolic 500 survey: characteristics of male users versus nonusers of anabolic-androgenic steroids for strength training. Pharmacotherapy 2011;31:757-66.

37. Noone A, Durante AJ, Brady AR, et al. HIV infection in injecting drug users attending centres in England and Wales, 1990-1991. AIDS 1993;7:1501-7.

38. Connell JA, Parry JV, Mortimer PP, et al. Novel assay for the detection of immunoglobulin $\mathrm{G}$ antihuman immunodeficiency virus in untreated saliva and urine. J Med Virol 1993;41:159-64

39. Judd A, Parry J, Hickman M, et al. Evaluation of a modified commercial assay in detecting antibody to hepatitis $\mathrm{C}$ virus in oral fluids and dried blood spots. J Med Virol 2003;71:49-55.

40. Health Protection Agency, Health Protection Services and Microbiology Services. Unlinked anonymous monitoring survey of people who inject drugs in contact with specialist services: data tables. London: Health Protection Agency, 2012.

41. European Centre for Disease Prevention and Control. Hepatitis $B$ and $C$ in the EU neighbourhood: prevalence, burden of disease and screening policies. Stockholm: European Centre for Disease Prevention and Control, 2010. http://www.ecdc.europa.eu/en/publications/Publications/ TER 100914 Hep B C\%20 EU neighbourhood.pdf

42. Health Protection Agency. HIV in the United Kingdom: 2012 Report. Colindale: Health Protection Services, 2012.

43. Magnani R, Sabin K, Saidel T, et al. Review of sampling hard-to-reach and hidden populations for HIV surveillance. AIDS 2005;19(Suppl 2):S67-72. 
44. Latkin CA, Vlahov D, Anthony JC. Socially desirable responding and self-reported HIV infection risk behaviors among intravenous drug users. Addiction 1993;88:517-26.

45. De Irala J, Bigelow C, McCusker J, et al. Reliability of self-reported human immunodeficiency virus risk behaviors in a residential drug treatment population. Am J Epidemiol 1996;143:725-32.

46. Lloyd-Smith E, Kerr T, Hogg RS, et al. Prevalence and correlates of abscesses among a cohort of injection drug users. Harm Reduct $J$ 2005;2:24.

47. Spijkerman IJ, Van Ameijden EJ, Mientjes GH, et al. Human immunodeficiency virus infection and other risk factors for skin abscesses and endocarditis among injection drug users. $J$ Clin Epidemiol 1996;49:1149-54.
48. Health Protection Agency, Health Protection Scotland, Public Health Wales, Public Health Agency Northern Ireland. Shooting up: infections among people who inject drugs in the UK 2011. London: Health Protection Agency, 2012.

49. Grimes DA, Lopez LM, Gallo MF, et al. Steroid hormones for contraception in men. Cochrane Database Syst Rev 2007:(2):CD004316.

50. Evans-Brown M, McVeigh J. Anabolic steroid use in the general population of the United Kingdom. In: Møller V, McNamee MJ, Dimeo P. eds Elite sport, doping and public health. Syddansk: University Press of Southern Denmark, 2009:75-97.

51. Bahrke MS, Yesalis CE. Abuse of anabolic androgenic steroids and related substances in sport and exercise. Curr Opin Pharmacol 2004 4(6):614-20 